Article

\title{
Technoeconomic and Policy Drivers of Project Performance for Bioenergy Alternatives Using Biomass from Beetle-Killed Trees
}

\author{
Robert M. Campbell ${ }^{1, *}$, Nathaniel M. Anderson ${ }^{2}$, Daren E. Daugaard ${ }^{3}$ and \\ Helen T. Naughton 1 \\ 1 Department of Economics, University of Montana, Liberal Arts Room 407, 32 Campus Dr., Missoula, \\ MT 59812, USA; helen.naughton@mso.umt.edu \\ 2 U.S. Forest Service, Rocky Mountain Research Station, 800 East Beckwith, Missoula, MT 59801, USA; \\ nathanielmanderson@fs.fed.us \\ 3 Cool Planet Energy Systems, 6400 South Fiddlers Green Circle, Greenwood Village, CO 80111, USA; \\ Daren.Daugaard@Coolplanet.com \\ * Correspondence: robert3.campbell@umontana.edu; Tel.: +1-406-542-4173
}

Received: 11 January 2018; Accepted: 24 January 2018; Published: 26 January 2018

\begin{abstract}
As a result of widespread mortality from beetle infestation in the forests of the western United States, there are substantial stocks of biomass suitable as a feedstock for energy production. This study explored the financial viability of four production pathway scenarios for the conversion of beetle-killed pine to bioenergy and bioproducts in the Rocky Mountains. Monte Carlo simulation using data obtained from planned and existing projects was used to account for uncertainty in key technoeconomic variables and to provide distributions of project net present value (NPV), as well as for sensitivity analysis of key economic and production variables. Over a 20-year project period, results for base case scenarios reveal mean NPV ranging from a low of $-\$ 8.3$ million for electric power production to a high of $\$ 76.0$ million for liquid biofuel with a biochar co-product. However, under simulation, all scenarios had conditions resulting in both positive and negative NPV. NPV ranged from $-\$ 74.5$ million to $\$ 51.4$ million for electric power, and from $-\$ 21.6$ million to $\$ 246.3$ million for liquid biofuels. The potential effects of economic trends and public policies that aim to promote renewable energy and biomass utilization are discussed for each production pathway. Because the factors that most strongly affect financial viability differ across projects, the likely effects of particular types of policies are also shown to vary substantially.
\end{abstract}

Keywords: technoeconomic analysis; beetle kill; woody biomass; bioenergy; biofuels

\section{Introduction}

Currently, $46 \%$ of all renewable energy in the United States (U.S.) comes from biomass, which accounts for $4.6 \%$ of total national energy consumption [1]. As such, bioenergy is anticipated to play a key role in the country's ability to meet renewable energy goals set by legislation such as the Energy Independence and Security Act of 2007 [2]. Many U.S. states also have renewable energy goals that explicitly include woody biomass utilization [3,4]. The U.S. Department of Energy estimates that, depending on price and policies over the next 20 years, woody biomass in the form of logging residues may provide between 16.2 and 18.9 million dry tonnes of biomass per year for energy [5]. Biomass energy can provide greenhouse gas benefits under certain conditions, such as in the case of residues from forest management activities in disturbance-prone ecosystems [6,7].

In the Rocky Mountain region of the western U.S. (Figure 1), there are substantial stocks of woody biomass associated with meeting forest management needs. Large areas of forest have become densely 
overstocked and substantially departed from historic, fire-resilient conditions because of decades of fire suppression, livestock grazing, and poor timber harvesting practices [8,9]. It is widely acknowledged that these conditions, together with climate change, have contributed to the escalating extent $[10,11]$ and severity $[12,13]$ of wildfire in the region. Furthermore, there is evidence that dense forests coupled with warmer winters and prolonged drought led to the largest bark beetle outbreak ever recorded in North America [14,15]. In Colorado, over 6.6 million acres of forestland have been negatively affected by the mountain pine beetle [16], with similar landscape-scale impacts caused more recently by the spruce bark beetle [17].

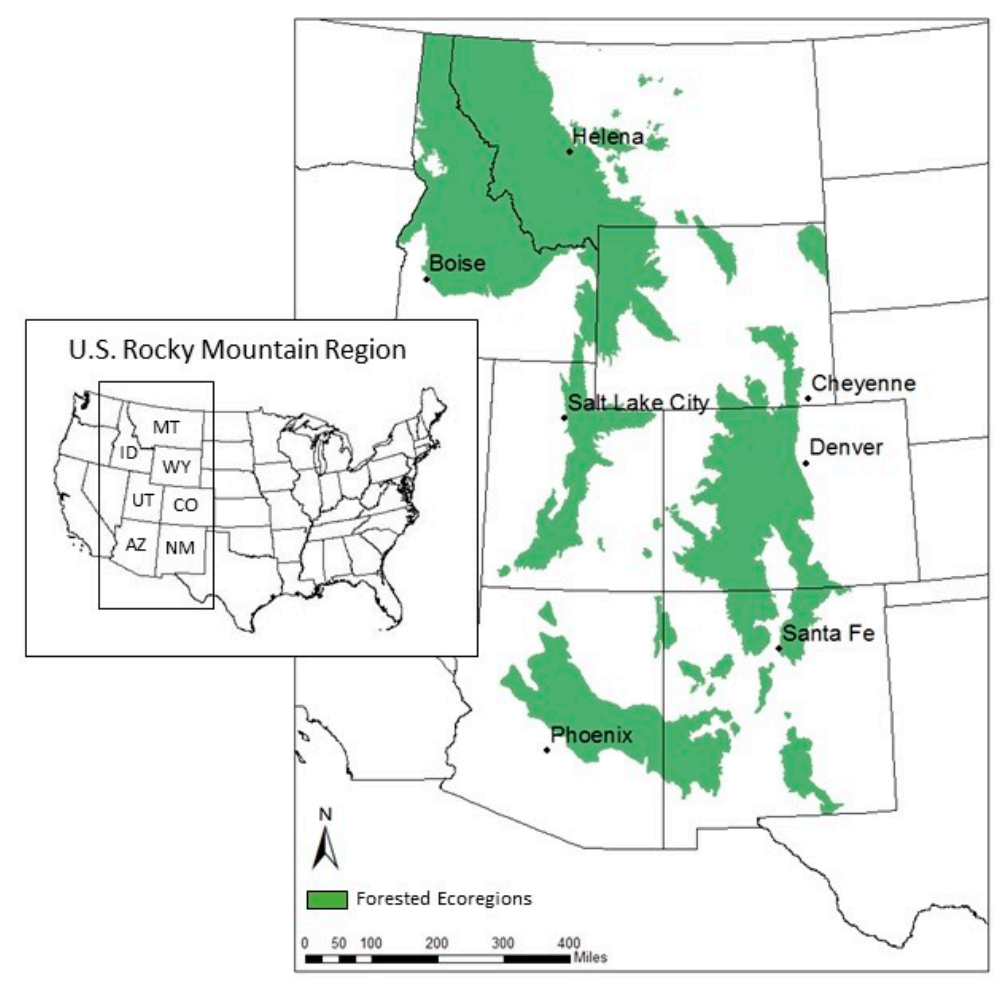

Figure 1. Study area map.

In response to these challenges, forest managers frequently prescribe silvicultural treatments to reduce stocking in dense forests to alter fire behavior (i.e., fuel treatments) and to harvest beetle-killed trees in stands with high mortality following an infestation (i.e., salvage harvests). Such treatments can be a substantial source of woody biomass feedstock for bioenergy production for several reasons. First, compared to green stands managed commercially, much of the volume cut in these treatments is not suitable for conventional solid wood products because of its small diameter or poor quality. Fuel treatments tend to remove smaller sub-dominant trees, leaving behind the larger diameter, green trees. Stands with substantial mortality are often affected by defects such as stain, rot and cracking, especially if there is a long delay between infestation and harvesting. Second, in some areas a portion of this material can be used as pulpwood for paper and other products, but those markets are long distances from much of the interior western U.S., limiting options for selling low-grade wood fiber. Third, the disposal by burning of unmerchantable biomass is frequently desired or required to reduce fire risk and improve site conditions for regeneration, but has negative impacts on local air quality. These characteristics present a unique opportunity to use forest biomass from fuel treatments and salvage harvests as feedstock in the production of renewable energy.

Despite its promise, such use can be financially challenging, with high production costs relative to fossil fuels creating barriers to growth [18]. Harvesting, collecting, processing, storing and transporting woody biomass feedstock can be quite expensive and can result in costs that exceed the delivered 
value of the feedstock for energy [19]. Financial challenges are also present on the demand side of the equation. Biomass can be converted into electricity, heat, and liquid and solid biofuels through a variety of conversion technologies, including combustion, pyrolysis, gasification and pelletization $[20,21]$. These technologies sometimes produce valuable co-products such as biochar, which is a high-carbon charcoal used as a soil amendment. However, technologies can differ substantially in terms of the overall complexity of the production process, as well as key production variables such as capital expenditures, operations costs, workforce requirements, and feedstock specifications. These technologies also tend to compete directly with fossil fuel-based technologies. As a result, technologies differ substantially in terms of net cost of production and substitutability, as well as the degree to which specific process variables impact production costs. Despite such variability among technologies, feedstock cost is cited almost universally as an important variable in determining project financial performance.

Given both the importance of and wide variation in the cost of forest-based bioenergy feedstocks, and the variety of energy conversion technologies that exist, there is a need to better understand how different conversion options compare to one another under alternative feedstock scenarios and what variables are most important in determining project success. This information is critical in developing effective policies aimed at increasing renewable energy production from woody biomass. This research contributes to filling this knowledge gap by: (1) conducting a technoeconomic comparison of four bioenergy technologies using woody biomass from beetle-killed trees to explore the relative importance of different economic and production variables on financial viability; and (2) discussing implications of these results for public policy and project investment.

\section{Technoeconomic Analysis of Woody Biomass Energy}

Technoeconomic analysis (TEA) is a modeling process that combines benefit-cost analysis with a detailed technical specification of a technology being evaluated [22]. TEA can be used to determine the potential economic viability of energy generation technologies and can help determine which technologies have the highest potential for success under specific conditions. TEA can also help identify the factors to which profitability is most sensitive and guide decisions about research and development toward areas where improvements will result in the largest cost reductions. When conducted well, TEA provides a standardized approach that facilitates accurate comparison of project alternatives, and it has been used to evaluate a wide range of bioenergy, biofuels and bioproducts technologies using woody biomass as feedstock.

An early TEA of bioenergy analyzed electricity generation in the United Kingdom using multiple different technologies and concluded that financial viability can be enhanced through, among other things, renewable energy financial incentives, high electricity prices, opportunities to procure feedstock from a waste-stream at negative cost, combined heat and power production, and the sale of co-products such as biochar [23]. The majority of TEA since then have found that at least one of those recommendations were major factors in determining the financial viability of bioenergy production.

An analysis of gasification of forest residues to produce biofuels and chemicals in a 2000 dry tonne per day plant in Western Canada, found the production of biomass based fuels to be expensive relative to fossil fuels, with carbon credits in the range of $\$ 50$ to $\$ 120$ per tonne offering a potential mechanism to improve competitiveness [24]. In a study that analyzed pyrolysis and gasification of pine, it was found that gasification was able to produce methanol at prices competitive with fossil fuels at scales larger than 100 tonnes per hour (h), but pyrolysis was only competitive when biochar was considered as a revenue generating co-product [25]. Financial viability was sensitive to the selling price of biochar, with the break-even selling price between $\$ 220$ and $\$ 280$ per tonne. Results from a technoeconomic assessment of co-firing with beetle-killed biomass in existing coal fired power plants in Colorado and Wyoming showed that co-firing increases the cost of electricity production between $1 \%$ and $9 \%$ depending on the plant and the percent of coal offset with biomass [26]. With a subsidy of $\$ 219,000$ per square kilometer of forestland treated to supply the biomass feedstock (\$2190 per hectare), the majority 
of cases considered resulted in reduced production costs relative to coal-only options. Liquid biofuels produced with wood chips have the potential to be competitive with their fossil derived equivalents, with fast pyrolysis and hydrotreating bio-oil in a 2000 tonne per day plant able to produce a gasoline and diesel blendstock with a minimum fuel selling price of $\$ 3.39$ per gasoline gallon (gal) equivalent (2011 dollars, $\$ 0.89$ per liter gasoline equivalent) [27]. However, that analysis included advancements that did not reflect the current state of commercially-available technology, which were targeted to be achieved by 2017 [27].

Studies like these have provided valuable insights to guide entrepreneurs and policy makers, and factors such as financial incentives, high energy prices, low cost feedstock, combined heat and power production, and the manufacture of co-products have become generally accepted as key determinants of project financial performance. However, at least three important conditions necessitate the ongoing use of TEA research to inform industrial decision making and public policy: the continuous development and deployment of new bioenergy technologies; variable conditions at the regional and local levels, including the evolution of feedstock supply chains to incorporate new sources of biomass from multiple sectors; and the shifting policy environment. Furthermore, because many existing TEAs focus on a single technology, there is a need for comparative TEA that evaluates technology alternatives using a standardized methodology and common set of assumptions.

\section{Methods}

This study used TEA with Monte Carlo simulation of uncertain inputs to compare four bioenergy options: liquid biofuel with biochar coproduct (Biofuel Scenario), wood pellets with biochar coproduct (Pellet Scenario), institutional-scale biomass heating (Heat Scenario), and utility-scale power production (Power Scenario). These four scenarios were chosen to represent different existing or planned energy conversion technologies in the Rocky Mountain region. Analysis of production technologies that are already deployed in the study region is a logical starting point to address the issue of efficient use of woody biomass from beetle killed forests because public policy and market forces have thus far supported their construction and operation, and market transaction evidence exists to benchmark specific costs and revenues. Although both the Biofuels and Pellet scenarios produce biochar as a co-product, a Biochar-only Scenario was not considered in this study because we were unable to obtain comparable data and information about a commercial facility operating at scale. This section proceeds first with a detailed explanation of assumptions and data sources, followed by descriptions and schematic diagrams of the production technologies represented in each scenario, then a description of the economic analysis conducted, and finally Monte Carlo simulation methods are explained.

Information on the production technologies used to characterize the four scenarios was collected from three sources: industry partners operating or planning similar facilities in the region, the primary literature focused on TEA of bioenergy and bioproducts, and engineering textbooks focused on facility design, construction and operation. Some additional information was provided in published sources by government agencies such as the National Renewable Energy Laboratory (NREL), the U.S. Energy Information Administration (EIA), the U.S. Department of Labor, and in rare cases by industry experts through personal communication. Though industry partners and experts contributed important information to the analysis, the four scenarios developed and analyzed here do not represent specific operations as they exist or as they are planned on the ground, but were developed as generalized scenarios that best combine diverse information from these sources in ways that facilitate independent replication, transparent interpretation, and broader application.

To make the results comparable between scenarios, an identical methodology is used to evaluate each scenario, and wherever possible identical assumptions are made for all scenarios. However, because there are substantial differences in the technologies in terms of products, production capacity, and capital investment required, scenario specific assumptions are required for some variables. All facilities are assumed to be based in the U.S. state of Colorado because it is one of the states most 
severely impacted by bark beetles, all of the partner facilities were located there, and this assumption removes variability that might otherwise be attributed to location.

All scenarios are treated as $n$th plant analyses, meaning that technologies are treated as mature, with several plants already constructed and operating [27]. Under $n$th plant assumptions, additional costs that are associated with a first-of-a-kind plant are not included in accounting. Such costs typically include special financing, equipment redundancies, research and development costs for new technologies, and extended startup periods [27].

A common starting point in the production process was used for all scenarios in this analysis, with standard size wood chips delivered to the factory gate and purchased on a dry weight basis. Tonne is a metric unit of mass equal to $1000 \mathrm{~kg}$, and is called a "metric ton" in the United States. "Dry weight basis" represents a unit of measure equal to the mass of the feedstock minus the mass of the water content, and does not necessarily mean that the biomass contains no moisture upon delivery. Both are used here because they are conventional in the industry. Unless otherwise noted, feedstock mass is referred to on a dry weight basis.

Wood chip size specifications are set at less than $7.62 \mathrm{~cm}$ ( 3 inches) in the longest dimension with no more than $10 \%$ overrun (i.e., less than $10 \%$ of the delivery falling outside that specification). In the Rocky Mountains, moisture content can range from 15\% moisture in wood chips from standing dead trees to $50 \%$ or more in chips from live trees. The mean delivered cost of wood chips was set at $\$ 40$ per dry tonne, consistent with other technoeconomic analysis of forest biomass based energy production [24], the U.S. Department of Energy Billion-Ton Report [5], which considers a range from $\$ 36$ to $\$ 73$ per tonne ( $\$ 40$ to $\$ 80$ per short ton), and price information from industry partners. Many conversion technologies require a narrower feedstock specification than this in terms of size, shape, particle homogeneity or moisture content, and additional pre-processing was taken into account on a scenario-specific basis. All of the scenarios included equipment to dry, size and screen this standardized chipped material on-site to correct specifications as required by the technology. Key economic and production parameters for the scenarios are presented in Table 1.

Table 1. Description of scenarios. MM: million.

\begin{tabular}{|c|c|c|c|c|}
\hline & \multicolumn{4}{|c|}{ Alternative Scenarios } \\
\hline & 1. Biofuel & 2. Pellet & 3. Heat & 4. Power \\
\hline Production technology & Pyrolysis & Pellet mill with gasifier & Commercial boiler & $\begin{array}{l}\text { Combustion with } \\
\text { steam turbine }\end{array}$ \\
\hline Primary product & Biofuel & Wood pellets & Thermal energy & Electricity \\
\hline Co-product & Biochar & Biochar & None & None \\
\hline $\begin{array}{c}\text { Feedstock processing } \\
\text { capacity }\end{array}$ & $10 \mathrm{th}^{-1}$ & $9 \mathrm{th}^{-1}$ & $0.4 \mathrm{th}^{-1}$ & $10 \mathrm{th}^{-1}$ \\
\hline Primary product yield & 1.8 MM gal & $56,500 \mathrm{t}$ & 22,400 MMBtu & $89,100 \mathrm{MWh}$ \\
\hline Co-product yield & $17,700 \mathrm{t}$ & $620 \mathrm{t}$ & NA & NA \\
\hline Total Capital Investment & $\$ 80.0 \mathrm{MM}$ & $\$ 18.3 \mathrm{MM}$ & $\$ 680,000$ & $\$ 39.3 \mathrm{MM}$ \\
\hline Annual operating costs & $\$ 11.3 \mathrm{MM}$ & $\$ 6.2 \mathrm{MM}$ & $\$ 84,000$ & $\$ 5.1 \mathrm{MM}$ \\
\hline Annual labor costs & $\$ 2.6 \mathrm{MM}$ & $\$ 1.0 \mathrm{MM}$ & $\$ 11,000$ & $\$ 0.9 \mathrm{MM}$ \\
\hline Annual operating time & $6570 \mathrm{~h}$ & $7446 \mathrm{~h}$ & $5256 \mathrm{~h}$ & $7884 \mathrm{~h}$ \\
\hline
\end{tabular}

\subsection{The Production Scenarios}

\subsubsection{Biofuel with Biochar Scenario}

The first scenario represents liquid biofuels and biochar production via pyrolysis (Figure 2). Bio-oil, also known as pyrolysis oil, is the condensed liquid product most often associated with pyrolysis [20]. However, in this case, pyrolysis is used to generate vapors that are catalytically converted to liquid fuel. This process has a lower liquid yield by mass than bio-oil production via condensation, but generates a near "drop-in" liquid biofuel with characteristics of near zero oxygen and benzene content that can be blended with petroleum gasoline. Because this process requires relatively narrow specifications 
for feedstock size and moisture content, it begins with on-site chipping, screening and drying of delivered wood chips. When the proper size and moisture content are achieved, the wood chips are fed through a lockhopper feed system into a pyrolyzer. Both the dryer and the pyrolyzer require natural gas or light gas for heating. In the pyrolyzer, wood chips are heated in the absence of oxygen until energy-rich vapors and light gases are produced. The remaining mass fraction is processed into a biochar co-product. Energy-rich vapors are interacted with a catalyst to produce a mixture of water, light gases, and biofuel, which are uncoupled in a separation step. In both the pyrolysis and the liquid separation phases, light gases with relatively low energy content are either flared or returned to the feedstock dryer through a recycle system to produce process heat. After the liquid separation phase, the raw biofuel mixture undergoes distillation into gasoline, diesel, and other fuel grades. In the base case, both the biochar and fuel yields used in the analysis are empirical outcomes from processing beetle-killed pine on large scale pilot systems using this technology. Natural gas, electricity, diesel, nitrogen, and catalysts are all consumed in this process and are accounted for as operating costs.

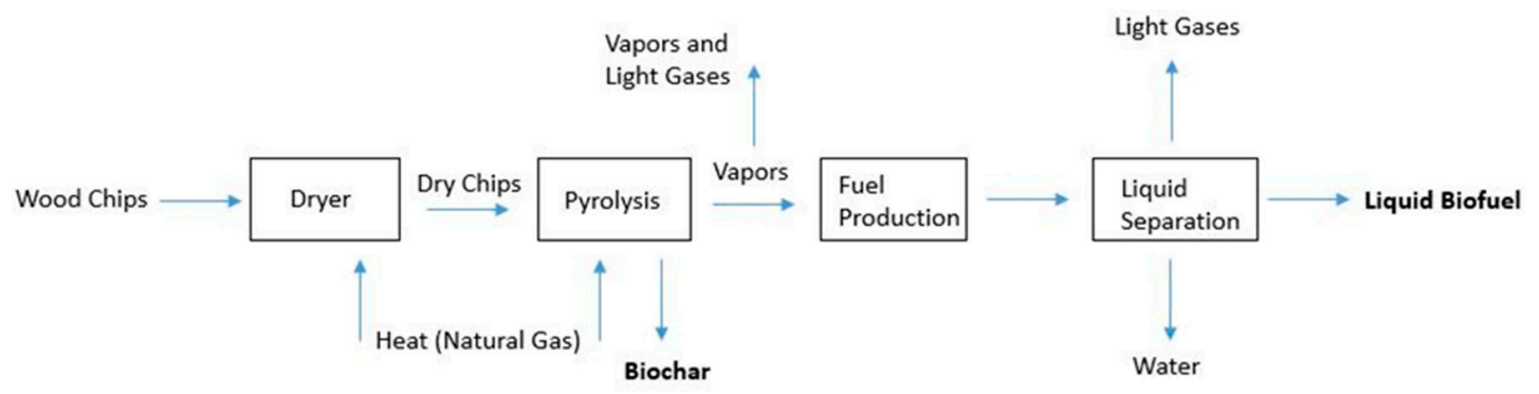

Figure 2. Schematic diagram of liquid biofuels production via pyrolysis with biochar co-product.

\subsubsection{Pellet Scenario}

The second scenario represents a wood pellet production facility (Figure 3). In the pellet facility, delivered biomass is first reprocessed in a chipper, and then transported via conveyor into a rotary dryer. Dried wood chips flow into a cyclone to separate particles of different sizes. Dry chips of the appropriate size are then processed into saw dust in a hammer mill and the sawdust is then fed into a pellet mill that presses the sawdust into pellets. Because of the high heat of the pellets when they come out of the pellet mill, they pass through an air-cooling unit. After cooling, pellets are packaged into retail-sized $20 \mathrm{~kg}$ bags. Packaging and shipping materials are accounted for in annual operating costs.

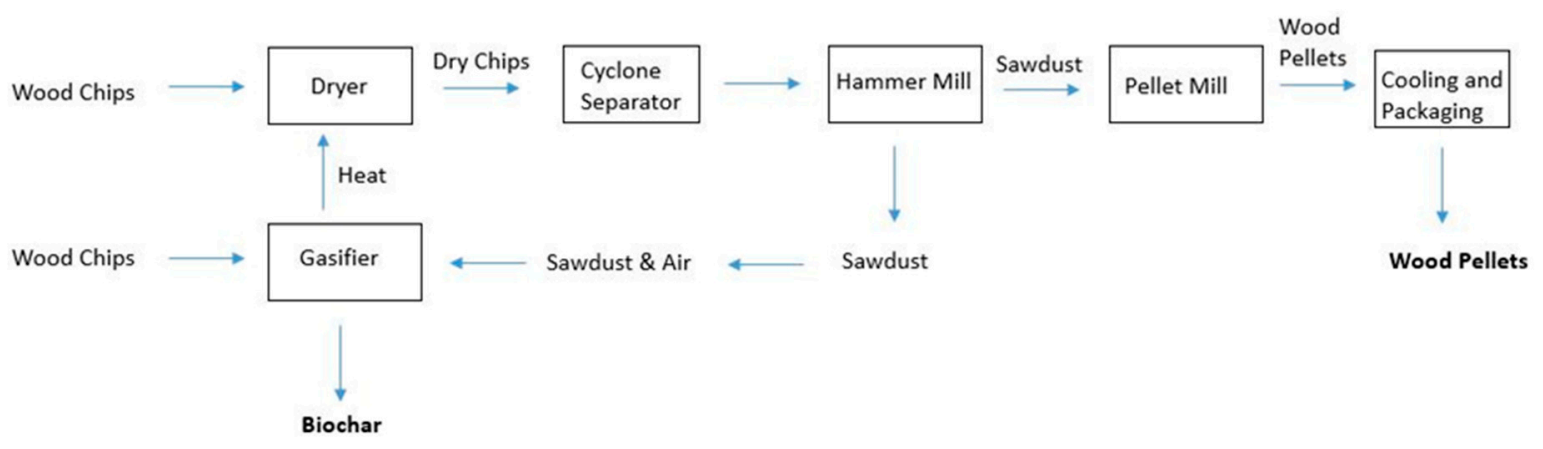

Figure 3. Schematic diagram of process heat from gasification with pellet and biochar production.

Drying is an essential component of the process because a relatively low moisture content must be achieved before processing in a hammer mill. Drying generally requires substantial energy inputs, often natural gas, accounting for around $70 \%$ of utility requirements [28,29]. Alternatively, woody biomass can be combusted or gasified instead of fossil fuels to provide the necessary heat to dry the 
feedstock and offset the cost of fossil fuel inputs. A common practice in the forest sector is to use woody biomass combustion or gasification to produce heat or combined heat and power for manufacturing processes. In this scenario, the thermal energy is produced in a gasifier unit that combusts sawdust that is blown into the unit with air. The remainder of the utility requirements are accounted for at market rates for electricity in Colorado [30]. Unconventionally, this system also incorporates a pyrolyzer tube into the gasifier unit that carbonizes additional woodchip inputs and produces biochar as a co-product that provides an additional source of revenue.

\subsubsection{Heat Scenario}

The third scenario represents thermal energy production via combustion at a distributed-scale thermal power plant appropriate for heating large buildings or complexes of buildings like schools and other institutions (Figure 4). This scale system typically operates at 3-4 MMBtu per hour capacity. In this process, wood feedstock is combusted to heat water that is transported through insulated piping to multiple buildings to supply heating requirements. Feedstock requirements for this process are relatively flexible. Feedstock can be $4-6$ inches long and does not have to be in a chip shape. A wide range of moisture content is acceptable (up to $40 \%$ ), implying that in most cases active drying of feedstock is not necessary, but dry feedstock does have advantages in terms of system efficiency.

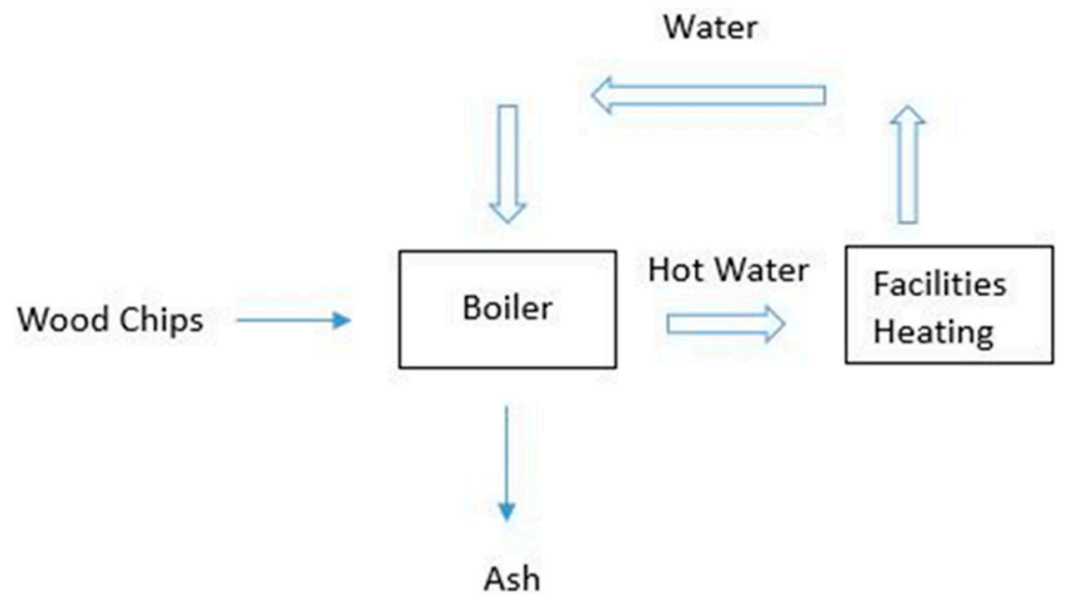

Figure 4. Schematic diagram for institutional heating.

Typically, feedstock is moved on demand using a front-end loader into the boiler building and stored in covered bays for up to two weeks. Some drying occurs incidentally while stored in the bays, but no additional drying is required. An automated auger system feeds wood onto a conveyor belt and into the boiler as needed, based on a laser sensor. The system was sized to provide $80 \%$ of required heating capacity on the coldest days of the year and requires a backup natural gas boiler for situations when the wood boiler is idled for ash removal or when the outside temperature is low enough that additional heating is needed, typically $-12{ }^{\circ} \mathrm{C}$ or lower. This backup system is included in the accounting.

A defining characteristic of the technology in the heat scenario is that it is highly automated. Very little labor is required to operate the facility once it is up and running. Other than manual transport of the feedstock from outdoor storage site into the indoor bays and periodic manual ash removal, which requires only a few hours per week, the system is entirely automated. At $60 \%$ capacity factor, the heat scenario has a lower capacity factor than the other scenarios because it is only in operation during the colder months when heat is required. 


\subsubsection{Power Scenario}

The fourth scenario represents electricity generation through combustion at the $11 \mathrm{MW}$ scale (Figure 5). For this technology, feedstock specifications are relatively flexible. Wood chips are combusted in a furnace to create heat, which produces steam in a closed loop turbine system. The steam spins a turbine that powers a generator, which generates electricity. Electricity is then sent to the electric grid. After being used to spin the turbine, the steam travels to a condenser where it is cooled back into liquid water and recycled into the furnace. An automated ash removal system clears the furnace of ash. Although not included in this analysis, if the plant is co-located with a facility that requires heat in its production process, excess heat from the furnace can be utilized in the second facility. Electricity use in the plant is the major utility cost for this scenario. This can be provided either by the facility itself as a portion of production, or by pulling power from the grid for operations. In this case, based on information provided by an industry partner, the facility sells all of the electricity produced and draws the electricity required to run the plant from the grid, with annual electric costs equal to $14 \%$ of annual revenues.

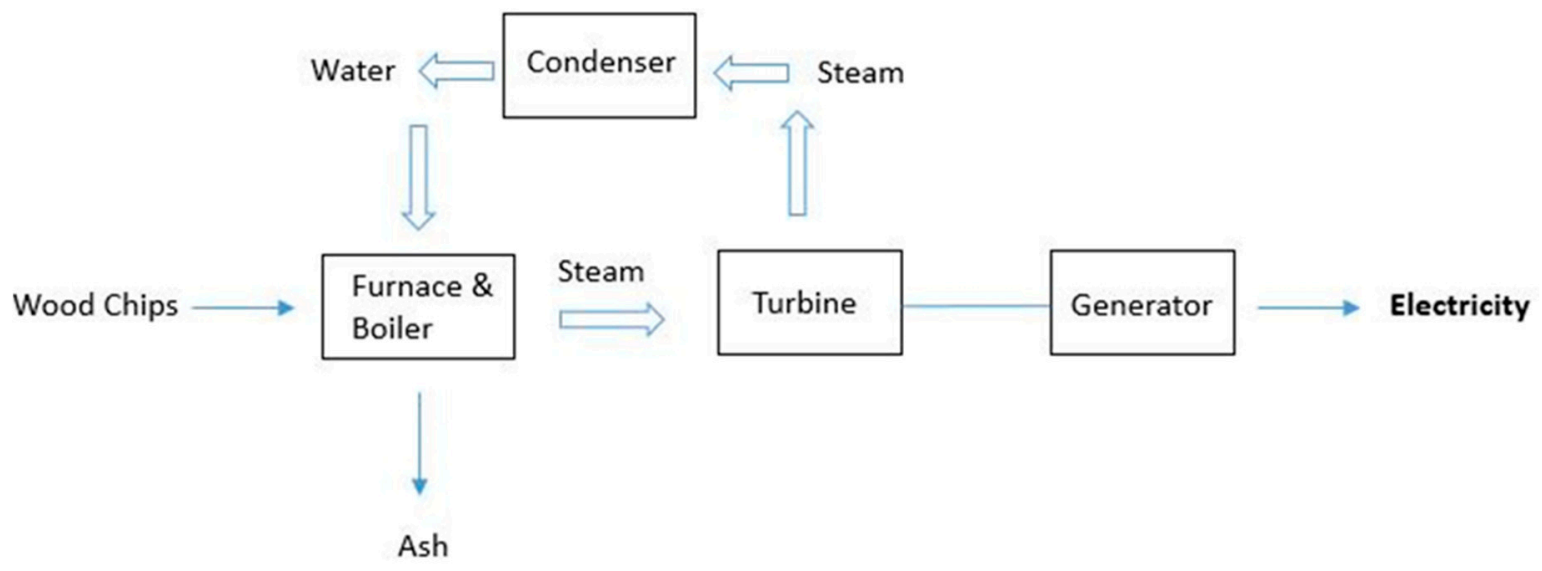

Figure 5. Schematic diagram for utility-scale power production.

\subsection{Economic Analysis}

Financial performance of each scenario was evaluated for an assumed 20-year facility lifetime, using discounted cash flow analysis to calculate the net present value (NPV) of each operation. NPV is the sum of all current and future cash flows, with future costs and revenues discounted to present values, as shown below.

$$
\mathrm{NPV}=\sum_{1}^{20} \frac{\left(\text { Revenues }_{t}-\text { Costs }_{t}\right)}{(1+r)^{t}}
$$

where $r$ is the discount rate, and $t$ is the year in which the revenues and costs are accrued, with Year 1 being the first year of operation. A mean discount rate of $10 \%$ was used to convert future values into present values, which is a rate commonly used in technoeconomic evaluation of bioenergy projects $[24,31,32]$. The discount rate in this case is composed of a riskless real rate of $3.0 \%$, which is comprised of a nominal rate of $2.5 \%$ and the long-run inflation rate of $0.5 \%$, and an implied risk premium of $6 \%$. A $6 \%$ risk premium was selected as a conservative estimate in this case to quantify risks in both production and product marketing, with the novelty of energy products and co-products analyzed ranging from emerging technologies to proven commercial technologies. It is likely that the risk premium would be higher for first plant development, but as stated previously, all analyses are conducted under $n$th plant assumptions. For a specific project, the internal rate of return of the project is the discount rate at which the net present value equals zero. Key financial accounting assumptions are shown in Table 2. 
Table 2. Financial accounting assumptions.

\begin{tabular}{ccc}
\hline Variable & Value & Source \\
\hline Discount rate & $10 \%$ & {$[24,31,32]$} \\
Loan financing & $80 \%$ loan financed & {$[31]$} \\
Loan interest rate & $8 \%$ APR a & {$[22,27]$} \\
Loan term & 10 year payback period & {$[22,27]$} \\
Federal income tax rate & $35 \%{ }^{\text {a }}$ & {$[33]$} \\
Plant life & 20 years & {$[32,34]$} \\
Depreciation & Straight-line method, 10 & {$[33]$} \\
Insurance and local taxes & years, zero salvage value & {$[33]$} \\
\hline
\end{tabular}

Note ${ }^{a}$ : Annual percentage rate (APR). ${ }^{\text {b }}$ Total capital investment (TCI). Income taxes for institutional heat are zero because energy product is not sold so no income is generated. Likewise, insurance and local taxes are not applied to institutional heating.

Revenues are calculated using production data from industry partners (Table 1) and product selling prices (Table 3), based on historic market price data where available. For products with less well-established markets, like biochar, prices are determined based on actual transactions made by industry partners in the region, checked against values in the literature. Revenues and operating costs are partially a function of the number of hours annually that each facility operates. Annual operating hours varies between scenarios and was determined based on empirical data from industry partners. Costs consist of capital investment and annual operating costs. Capital costs are based on information provided by partner facilities, and on published estimates, and are presented in terms of 2015 U.S. dollars.

The total capital investment (TCI) of a scenario is the sum of fixed capital investment (FCI) and working capital. FCI reflects the cost of building and equipping a plant. This includes the cost of engineering, construction, equipment purchase, installation of equipment, buildings, and land [35]. Because of differences in the technologies represented in each scenario, major equipment requirements vary substantially between the scenarios. Included equipment is "within factory gates," and does not include transportation equipment and infrastructure associated with feedstock harvest and transportation or shipping and delivery of energy products. On the feedstock supply side of the gate, logistics costs for feedstock (i.e., harvest, preprocessing and transportation) are included in the $\$ 40$ per tonne price, but feedstock storage and processing to narrower specification is considered inside the gate for all scenarios. On the product demand side, packaging of physical products is considered to be inside the gate, but down-stream logistics are outside the gate. Working capital is added as a fixed percent of FCI to account for capital costs associated with day-to-day plant operations like accounts receivable, cash on hand, and raw material and product inventory, and is recouped in the last year of the analysis [35].

Operating costs are incurred continually throughout the life of the plant and are accounted for on an annual basis. Operating costs include feedstock, maintenance, utilities, consumable inputs (e.g., catalysts and chemical inputs), and waste disposal. Labor costs are accounted for separately. Because the scenarios represent different energy production technologies, specific types of operating costs differ across scenarios. Operating costs are based on information provided by partner facilities where available, and on values from the literature where necessary. Labor requirements were provided by the partner facilities, and combined with national wage rate data from the U.S. Bureau of Labor Statistics for chemical manufacturing, wood product manufacturing, and biomass electricity plants depending on the job description and scenario [36]. Maintenance costs are accounted for as 5\% of TCI for the Biofuel Scenario and the Pellet Scenario [33], \$0.50 per MMBtu produced for the Heat Scenario (based on an economic analysis of a similar system in Darby, Montana [37]), and 7\% of gross revenue for the Power Scenario. 
Although NPV is a valuable measure of the financial viability of each scenario, because of the differences in the scale of investment required and production capacity of the scenarios in this analysis, NPV does not necessarily facilitate comparison among the scenarios. In other words, it is unlikely that a firm would be evaluating either an investment in a single $\$ 80$ million biofuel plant or 117 institutional heating facilities-these are quite different ventures in most respects. Additionally, because the end products differ between scenarios, metrics such as minimum fuel selling price and levelized energy cost, which are commonly used in TEAs that analyze a single technology, do not offer an informative measure of comparison between these scenarios. However, there is a common input across the scenarios that can be used for a level comparison-feedstock price. To compare scenarios with a level metric, the maximum feedstock price at which each scenario can maintain profitability $(\mathrm{NPV}=0)$ is used.

Monte Carlo simulation was used to account for uncertainty associated with some input variables, generate measures of statistical significance for NPV estimates, estimate maximum bearable feedstock price, and conduct sensitivity analysis. Separate simulation runs with 50,000 iterations were conducted using @Risk 7.5 software (Palisade Corporation, Ithaca, NY, USA) to obtain NPV estimates and maximum bearable feedstock price, and to conduct sensitivity analysis. Sensitivity analysis allows for the relative magnitudes of effects of different factors on NPV to be compared and for potential future conditions to be considered. Consideration of future scenarios, where conditions differ in some way from the modeled scenarios, is facilitated through sensitivity analysis of key production variables, allowing identification of a range of conditions that could result in net positive financial performance.

Monte Carlo simulation provides advantages in sensitivity analysis and accounting for uncertainty. Though deterministic sensitivity analysis is commonly included in economic analyses, it considers only changes in a single variable at a time, with other variables held constant. In contrast, sensitivity analysis using Monte Carlo simulation allows multiple parameters to vary simultaneously, providing a fuller analysis of the effects of the variable of interest across the input space. Monte Carlo simulation also accounts for uncertainty in the absence of independent observations of a variable of interest from which standard error and confidence intervals of parameter estimates could be calculated statistically. For example, in this case, we do not have independent observations of NPV for multiple operations using the same pathway, and uncertainty is quantified with a distribution of NPV values produced by sampling from distributions of values for uncertain inputs, including conversion rate and market prices of products.

Inputs in the discounted cash flow model that varied across a range of values include: capital costs, energy and co-product conversion rates, product selling prices, and the discount rate. All uncertain variables were defined with triangular distributions, with base-case values, ranges, and data sources shown in Table 4. Triangular distributions are continuous probability distributions defined by a minimum value, maximum value and mode, and are commonly used in business and finance when limited information is available to describe the true distributions of variables [38].

Table 3. Summary of uncertain inputs.

\begin{tabular}{cccccc}
\hline Variable & Scenarios & Minimum & Base-Case & Maximum & Source \\
\hline Discount Rate & All & $4 \%$ & $10 \%$ & $16 \%$ & {$[24,31,32]$} \\
Feedstock price & All & $\$ 0 \mathrm{t}^{-1}$ & $\$ 40 \mathrm{t}^{-1}$ & $\$ 80 \mathrm{t}^{-1}$ & Industry Partners; [24] \\
Fixed Capital Investment & All & $-30 \%$ & Scenario-specific & $+30 \%$ & Table 2 \\
Biochar conversion rate & Biofuel & $22 \%$ & $27 \%$ & $32 \%$ & Industry Partners \\
Biochar conversion rate & Pellet & $6 \%$ & $11 \%$ & $16 \%$ & Industry Partners \\
Biofuel conversion rate & Biofuel & $7 \%$ & $9 \%$ & $11 \%$ & Industry Partners \\
Pellets price & Pellet & $\$ 178 \mathrm{t}^{-1}$ & $\$ 200 \mathrm{t}^{-1}$ & $\$ 222 \mathrm{t}^{-1}$ & Industry Partners; [28] \\
Biochar price & Biofuel, Pellet & $\$ 899 \mathrm{t}^{-1}$ & $\$ 1834 \mathrm{t}^{-1}$ & $\$ 2,778 \mathrm{t}^{-1}$ & Industry Partners; [39] \\
Biofuel price & Biofuel & $\$ 1.59 \mathrm{gal}^{-1}$ & $\$ 2.36 \mathrm{gal}^{-1}$ & $\$ 2.96$ gal $^{-1}$ & [40,41] \\
Electricity price & Power & $\$ 50 \mathrm{MWh}^{-1}$ & $\$ 100 \mathrm{MWh}^{-1}$ & $\$ 150 \mathrm{MWh}^{-1}$ & Industry Partners \\
Heat price & Heat & $\$ 2.52 \mathrm{MMBtu}^{-1}$ & $\$ 5.35 \mathrm{MMBtu}^{-1}$ & $\$ 10.83 \mathrm{MMBtu}^{-1}$ & {$[42]$} \\
\hline
\end{tabular}


Table 4. Net present value (NPV) and ability to pay for feedstock.

\begin{tabular}{ccccc}
\hline & Biofuel Scenario & Pellet Scenario & Heat Scenario & Power Scenario \\
\hline Mean NPV at $\$ 40 \mathrm{t}^{-1}$ feedstock price & $\$ 76.0 \mathrm{M}$ & $\$ 22.4 \mathrm{M}$ & $-\$ 24,000$ & $-\$ 8.3 \mathrm{M}$ \\
Maximum feedstock price for NPV $=0$ & $\$ 227 \mathrm{t}^{-1}$ & $\$ 97 \mathrm{t}^{-1}$ & $\$ 39 \mathrm{t}^{-1}$ & $\$ 26 \mathrm{t}^{-1}$ \\
\hline
\end{tabular}

\section{Results}

Mean values of NPV are presented for each scenario in Table 4. The Biofuel Scenario has the highest mean NPV, at $\$ 76.0$ million over the 20 -year project period, followed by the Pellet Scenario with mean NPV of \$22.4 million. The Heat Scenario comes next, with a mean NPV that is just below zero, at $-\$ 24,000$. The Power Scenario has a mean NPV of $-\$ 8.3$ million, and is the only scenario with substantially negative mean NPV over the 20-year project period.

Figure 6 displays the distributions of NPV values produced by independent simulations of 50,000 iterations each. The distributions of all four scenarios overlap zero NPV, revealing that, within the range of conditions analyzed in this study, all four scenarios have the potential to be either profitable or unprofitable. The likelihood and magnitude of profitability varies substantially between scenarios, with both the Biofuel Scenario and the Pellet Scenario producing distributions that lay largely in the positive NPV space, and only a small amount of the lower tail of the distributions in the negative NPV outcomes (over $99 \%$ positive for the Biofuel Scenario and $98 \%$ positive for the Pellet Scenario). The distribution for the Heat Scenario, on the other hand, is centered close to zero, with an almost equal probability of a positive or negative NPV outcome across the analyzed range of conditions ( $46 \%$ positive). The distribution of the Power Scenario is mostly in negative NPV space, only resulting in positive NPV results under optimistic assumptions, with $30 \%$ of the 50,000 iterations resulting in positive NPV. NPV ranged from $-\$ 21.6$ million to $\$ 246.3$ million for the Biofuel Scenario, $-\$ 19.2$ million to $\$ 76.2$ million for the Pellet Scenario, $-\$ 1.7$ million to $\$ 1.9$ million for the Heat Scenario, and $-\$ 74.5$ million to \$51.4 million for the Power Scenario.
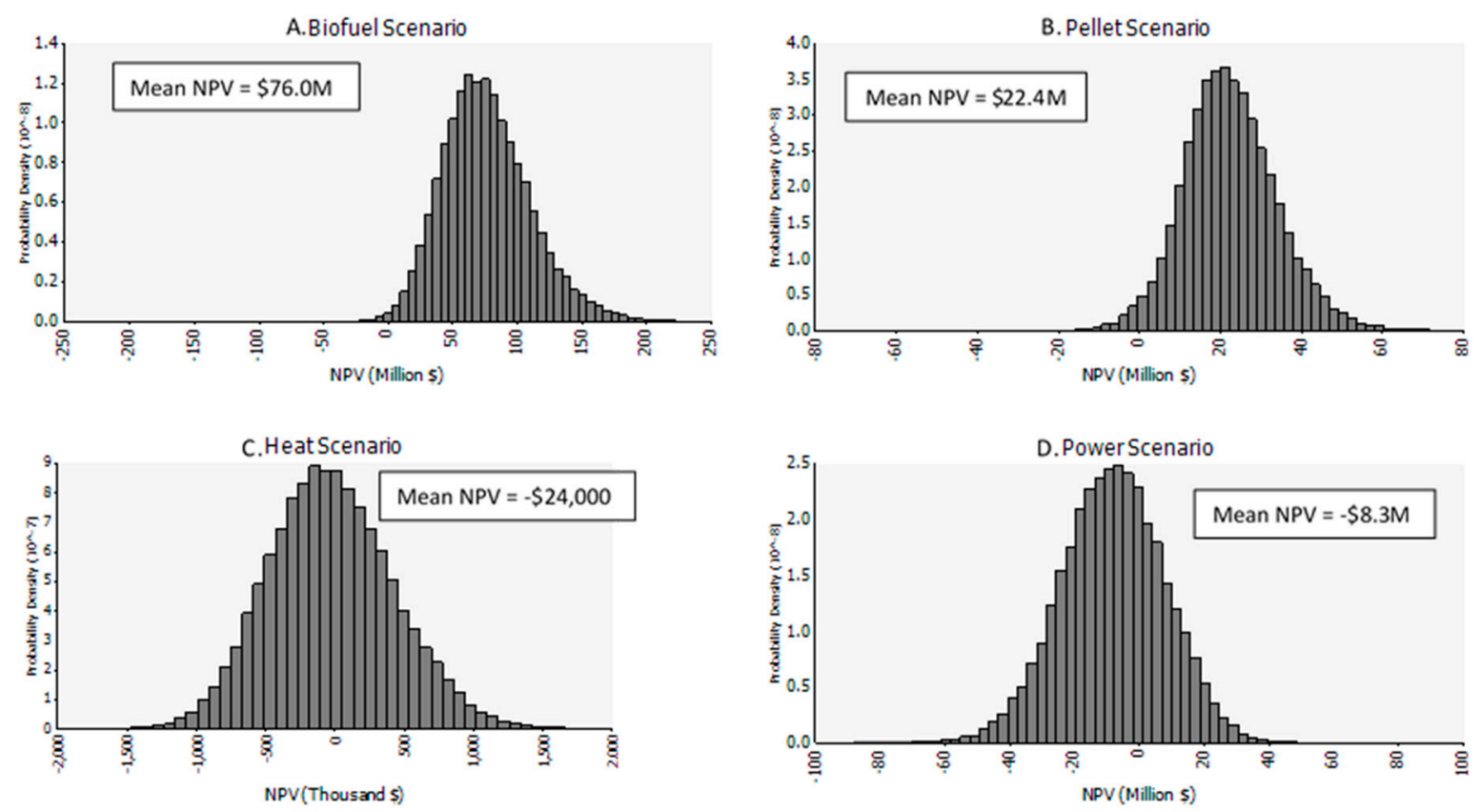

Figure 6. Histograms of Net Present Value (NPV) Distributions from Simulations of 50,000 Iterations, by Scenario. (A) Biofuel Scenario: $99 \%$ positive outcomes. Range from $-\$ 21.6$ million to $\$ 246.3$ million. (B) Pellet Scenario: $98 \%$ positive outcomes. Range from $-\$ 19.2$ million to $\$ 76.2$ million. (C) Heat Scenario: $46 \%$ positive outcomes. Range from $-\$ 1.7$ million to $\$ 1.9$ million. (D) Power Scenario: $30 \%$ positive outcomes. Range from $-\$ 74.5$ million to $\$ 51.4$ million. 
Figure 7 displays the effect that each uncertain variable has on NPV for each scenario, across the entire range of values in its distribution, while holding all other uncertain parameters at their base-case values. In each panel, the parameter on the top has the largest effect on NPV, while the parameter on the bottom has the smallest effect. This ranking is attributable to both the relative importance of the variable in the calculations and also the relative width of its defined distribution range.
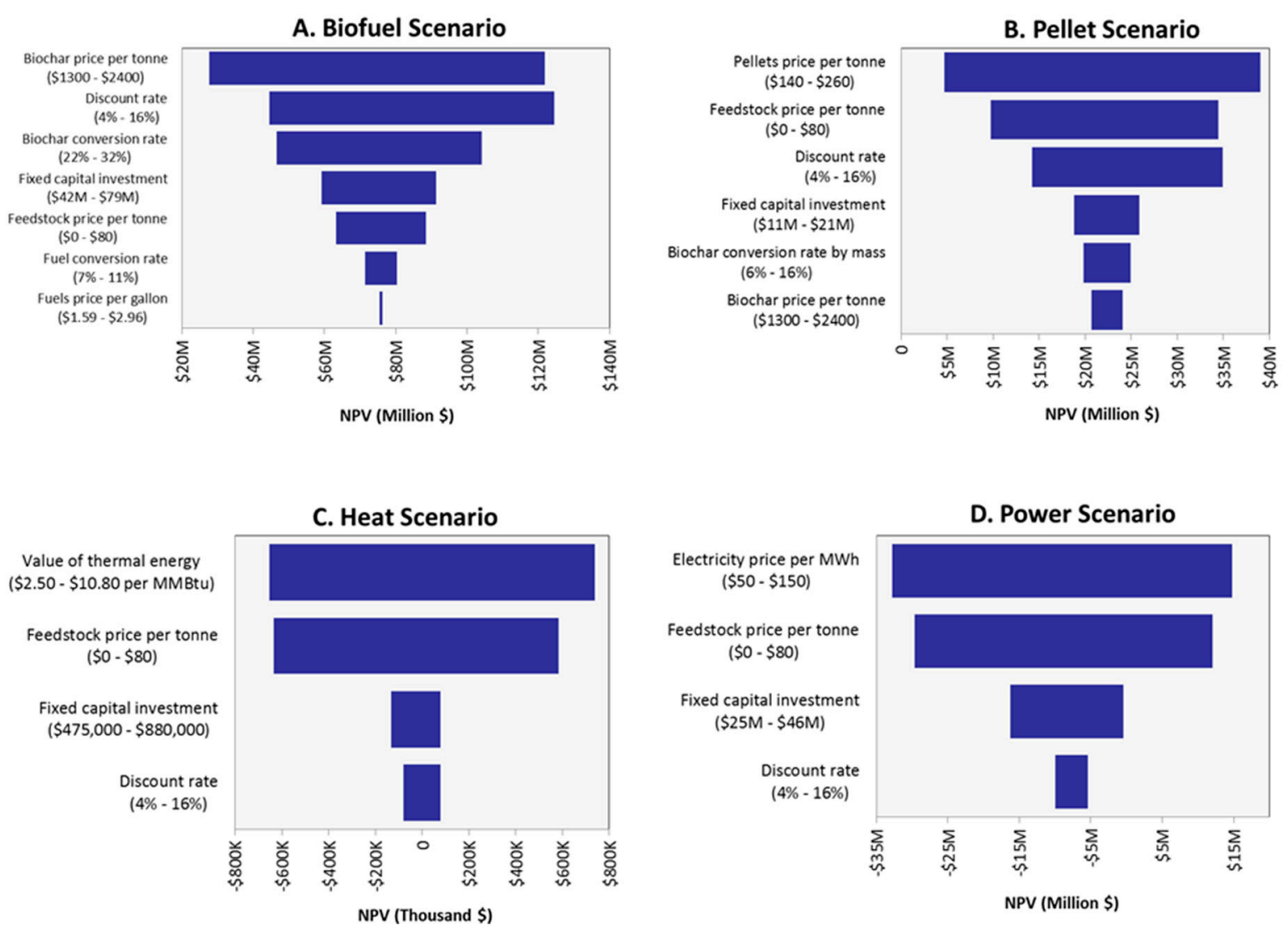

Figure 7. Tornado Graphs of Uncertain Parameters Ranked by Effect on NPV, by Scenario. (A) Biofuel Scenario: The price of biochar has the largest effect on NPV. Price and conversion rate of biofuel have the smallest effects. (B) Pellet Scenario: Price of pellets has the largest effect on NPV. Price of biochar has the smallest effect. (C) Heat Scenario: Value of heat has the largest effect on NPV. Discount rate has the smallest effect. (D) Power Scenario: Price of electricity has the largest effect on NPV. Discount rate has the smallest effect.

For the Biofuel Scenario, the price of biochar has the largest effect on NPV, while the price and conversion rates of biofuel have the smallest effects. This result is driven largely by the fact that a substantially larger proportion of each tonne of feedstock is converted into biochar than into biofuel, around a factor of three to one on a mass basis, so the effect of biochar price is magnified. The discount rate applied to future costs and revenues is the second most influential variable in determination of NPV. Capital investment has the fourth largest effect on NPV, followed by the price of feedstock, which is ranked fifth. Relative to other scenarios, the discount rate is ranked highest in the Biofuel Scenario tornado graph (Figure 7).

For the Pellet Scenario, the price of pellets has the largest effect on average NPV and the price and conversion rates of biochar have the smallest effects. This is similar to the influence of product price in the Biofuel Scenario: production output influences the relative importance of the two products, with pellets comprising a much larger portion of the output, even though biochar is the higher priced product. Feedstock price has the second largest effect on NPV, followed by the discount rate. Capital costs have the fourth strongest effect on NPV. 
The value of heat as the sole energy product in the Heat Scenario has the largest effect on average NPV. In this case, the value of heat represents the value of offset costs from producing an equivalent amount of heat with a substitute fuel, such as natural gas. High heating value can be more broadly interpreted as high cost of heating with a substitute fuel. As in the Pellet Scenario, the cost of feedstock is the second most influential uncertain variable. Capital investment and discount rate have the smallest effects on variability of NPV.

The price of electricity has the largest effect on average NPV of the Power Scenario. Recall that the facility in the Power Scenario produces only electricity, and no value is assigned to heat as would be done in a cogeneration scenario. This scenario produces positive NPV when the price of electricity is at or above $\$ 115$ per megawatt hour (MWh), which is less than the largest value in the range of $\$ 50$ to $\$ 150$ per MWh. The importance of the remaining uncertain variables follows the same order as the Heat Scenario. Notably, the discount rate has the smallest effect on the NPV in both the Heat and the Power Scenario. This is driven by small net revenues at the base-case electricity price and therefore the values being discounted are small relative to more influential factors like capital investment.

Maximum bearable feedstock price for each scenario is presented in Table 4. This price should not be interpreted as what the facility would actually be willing to pay for feedstock, but rather as a metric to compare the relative risk associated with feedstock procurement and its potential impacts on profitability. Recall that delivered feedstock is the same for all scenarios, with inside the gate processing taking the feedstock from its delivered specifications to any narrower specifications required by the technology. Not surprisingly given their NPV ranges, the Biofuel Scenario has the largest maximum bearable feedstock price at $\$ 227$ per tonne, and the Pellet Scenario has the second highest at $\$ 97$ per tonne. The Heat Scenario can bear $\$ 39$ per tonne while maintaining financial viability as reflected by positive NPV. The Power Scenario has the lowest ability to pay for feedstock, but can still pay a positive amount for feedstock, with zero NPV corresponding to a feedstock price of $\$ 26$ per tonne.

\section{Discussion}

Results of this TEA provide insights for firm-level decision making with regards to facility siting and investment of additional capital, which can reduce exposure to uncertainty in financial outcomes. Results can also inform government policy-making aimed at facilitating growth in the bioenergy and bioproducts industry in the Rockies, and at stimulating the use of feedstocks from forest sources, including harvest of trees killed by beetles and other insects.

\subsection{Industry Implications}

Given the much stronger effect of biochar price than capital costs on NPV for the Biofuel Scenario, additional processing of biochar to create product differentiation that could allow biochar to be sold at a premium price would provide financial benefits. Because the NPV of biofuel and biochar production is much more sensitive to the conversion rate of biochar than the conversion rate of biofuel, optimizing the system to maximize biochar production by operating at lower temperatures, at the expense of lower biofuel production, may be a viable tradeoff depending on market conditions. Unlike the other scenarios, in which profitability is highly dependent on the price of feedstock as the second most influential factor, feedstock cost is relatively less important for the Biofuel Scenario. This suggests that site selection in proximity to a supply of inexpensive feedstock is important for the Pellet, Heat and Power Scenarios, but less important for the Biofuel Scenario. For the Biofuel Scenario, proximity to refining capacity and biofuel markets seems to be more critical.

Because the price of pellets has the strongest effect on NPV for the Pellet Scenario, investing additional capital (which has a relatively weak effect on NPV) to enhance the ability to produce a higher quality or more differentiated product that would garner a price premium is likely to be a good tradeoff. Given the relative insensitivity to capital costs, additional capital investment that would allow the facility to produce process electricity in addition to the process heat provided by the gasifier would reduce operating costs and potentially improve profitability. 
Because the NPV of the Heat Scenario is close to zero, and is most sensitive to the cost of heating with a substitute fuel, changes in the price of substitute fuels have a large effect on whether or not the facility breaks even. For example, using the price per MMBtu with natural gas in the year of construction for the partner facility ( $\$ 10.81$ in 2005), the NPV of the project would be over $\$ 700,000$. Using the price of $\$ 2.52$ in 2016, the NPV is a loss of around $-\$ 600,000$ (Figure 6). However, the Heat Scenario represents a different type of investment decision than the other scenarios. Institutional heating facilities are most likely to be installed in public institutions, which, along with the goal of reducing heating costs, may be implemented to produce other socially desirable goals of offsetting fossil fuel use or using existing wood waste from nearby public lands as fuel.

Only $30 \%$ of iterations yield a positive NPV for the Power Scenario, and though the break-even energy price of $\$ 115$ per MWh is possible, it is well above the U.S. 2016 average price for industrial users (\$68 per MWh), but still below the U.S. 2016 average price for residential users (\$125 per $\mathrm{MWh}$ ). This comparison does not account for a price premium for renewable energy, but considers power price for all energy sources and all consumers. Obviously, a price premium for renewable energy on the residential market would factor more favorably in this case. The financial superiority of both the Biofuel and Pellet scenarios suggests that product diversification is a good strategy for profitability. Opportunity for the production of multiple products exists for power production as well, because heat produced in the electricity generation process could be sold to neighboring industrial facilities. Where opportunities exist, this would produce an additional revenue stream. In addition to being able to achieve NPV $=0$ with sufficiently high electricity selling prices ( $\$ 115$ per MWh), the Power Scenario could achieve NPV $=0$ at the base-case power price of $\$ 100$ per MWh by selling approximately 199,000 MMBtu per year at the long-run average price of $\$ 5.35$ per unit, which would require producing 2.6 MMBtu per tonne of feedstock in addition to the electricity produced, which is technically feasible. One dry tonne of wood chips contains about 18.7 MMBtu of energy and the efficiency of heat production in combined heat and power plants on average is $45 \%$ [43]. Producing 8.4 MMBtu tonne $\mathrm{M}^{-1}$ of the approximately 77,000 tonnes processed annually in the Power Scenario would be over $650,000 \mathrm{MMBtu}^{-1}$. These calculations assume no additional capital expenses to equip the plant for cogeneration and no reduction in electricity generation efficiency.

\subsection{Policy Implications}

Numerous policies that aim to promote renewable energy and the utilization of biomass have been enacted throughout the U.S. at both the federal and state levels. Polices aimed at promoting biomass utilization vary according to the type of policy (e.g., incentive, regulation, information), the step in the supply chain to which they apply (i.e., harvesting, transportation, processing, conversion, end use), and the sector that they target (i.e., industrial, commercial, residential). Often falling under the umbrella of public-private partnerships, such policies and the programs they establish can reduce costs, remove barriers to obtaining funding, and reduce the burden of risk on private business ventures by transferring some costs or portion of risk to the public. In exchange for this support, the public receives investments in renewable energy that have public benefits (e.g., reduction in greenhouse gas emissions, local economic development, etc.) and might not have taken place without public assistance. It has been noted that from a public perspective, conventional methods of evaluating financial viability, including this type of TEA, may be incomplete and alternative methods such as the Public Sector Comparator (PSC) can be used to compare outcomes to the cost of the public sector undertaking the project itself [44].

None of the scenarios in this study explicitly incorporated any such policy parameters in their base case or simulations, but potential effects can be examined based on the ranges of the variables and outcomes that were included in the TEA, and the intended or observed effects of policies applied. Given the ever-changing nature of the renewable energy and greenhouse gas emissions policy environment, by not including policy variables in the analysis, we hope interpretation of the results of the study will be less subject to the policy environment that existed during the period in time in which it was 
produced. Furthermore, because policy parameters were not included, PSC and other metrics were also not included, but results do point towards some interesting potential policy effects.

Economic incentives can reduce capital and operating expenses through tax breaks, project financing (loans, loan guarantees, and grants), direct payments for feedstock subsidies, or production payments like renewable energy credits (RECs) and feed-in tariffs [4]. Project financing policies lower the cost of financing bioenergy projects through low interest rate loans or through grants that do not require repayment. Policies such as these can benefit all types of bioenergy projects, but are especially important for liquid biofuels, which require the highest amounts of capital investment and would otherwise potentially be obtained through high interest rate loans because of the investment risk associated with novel technologies. Looking at the highest discount rate in this analysis (16\%) as a representation of a high rate of return that might be required for venture capital investors, the NPV of the Biofuel Scenario at $16 \%$ is substantially reduced to $\$ 44.6$ million from the $\$ 76.0$ million NPV at the mean discount rate of $10 \%$. In reality, expectations for returns from venture capital can be even higher than this, reinforcing the potential benefits of lowering capital costs in this sector. This strategy has been pursued by both the U.S. Department of Energy (DOE) and U.S. Department of Agriculture (USDA). For example, between 2008 and 2016, the USDA invested nearly $\$ 1$ billion in 230 wood energy projects through a combinations of grants, loans, and loan guarantees associated with various programs [45]. The DOE provides loans and loan guarantees to renewable energy projects through its Loan Programs Office, which provided a \$132 million loan guarantee for a 25 million gal per year cellulosic ethanol plant in Kansas in 2011 [46].

Reducing up-front capital costs appears to be important to facilities considering institutional biomass heating as well. For example, based on an informal internet search (in July 2017), at least 12 of the 14 institutional heating facilities in the state of Montana received a grant, loan, or loan guarantee to fund some portion of capital investment. This may help institutions justify bioenergy investment in the face of fuel price volatility over a 20 -year project period, such as the natural gas price range from $\$ 10.81$ per MMBtu in 2005 to $\$ 2.52$ per MMBtu in 2016, which was encountered by our partner facility. As described previously, in the Heat Scenario the price of alternative heating fuels, especially natural gas and fuel oil, had important implications for financial performance. Though there is currently no carbon tax implemented in the U.S., results show that a tax on $\mathrm{CO}_{2}$ emissions from fossil fuels would improve the cost competitiveness of biomass heat specifically, and bioenergy technologies in general, depending on how it was structured and implemented.

Production incentives essentially increase the effective prices received for each unit of energy produced. RECs allow credits associated with the amount of renewable energy produced to be sold in separate markets, that can be voluntary, or part of a compliance market associated with policies such as state-level renewable portfolio standards (RPS), which mandate that utilities and other energy purchasers receive a certain amount of their energy from renewable sources. The effect on bioenergy specifically from increased demand for renewable energy generally created by RPS requirements on bioenergy will depend on price competitiveness with other renewables, unless a specific biomass carve-out is included [47]. Feed-in tariffs provide a price premium and long-term purchase agreements with price stability, and are commonly designed to cover the levelized cost of energy production, plus a target return for investors, which is analogous to achieving NPV $=0$ in this analysis [48].

Given that the price received (or cost averted) for the main product was the strongest predictor of NPV across all scenarios, policies that increase the price received per unit produced would be beneficial to all types of producers in this study that sell their outputs. A REC or feed-in tariff worth $\$ 15$ per MWh would be required to bridge the gap between the $\$ 115 \mathrm{MWh}^{-1}$ breakeven selling price of the Power Scenario and the $\$ 100$ per MWh average wholesale electricity price used in this study. This is higher than the average price of voluntary RECs in the U.S. in 2014 of around $\$ 1$ per MWh [49]. However, REC prices vary substantially depending on energy type, geographic region, and market conditions, and RECs in state-level compliance REC markets have reached \$50 per MWh [49]. More generally, 30\% of simulation results for the Power Scenario were in positive NPV space without accounting for heat 
value, and the application of these types of economic instruments would push the distribution toward more positive outcomes.

Policies such as the federal Biomass Crop Assistance Program (BCAP) [50], provide direct matching payments on feedstock purchases made by eligible biomass energy facilities. Although the purpose of BCAP was to support suppliers of biomass feedstock, in essence the policy also reduces the cost of feedstock for eligible energy producers. Feedstock purchase subsidies are most likely to benefit electric power production, pellet manufacturing, and institutional heating applications, because of the high impact of feedstock cost on NPV for those scenarios. At the mean value used in this analysis of $\$ 40$ per tonne, producers could essentially be paying only \$20 per tonne. This would make the Power Scenario in our analysis break even on average across the simulation, given the maximum bearable feedstock price of $\$ 26$ per tonne.

Operations in this study were assumed to be based in Colorado, but it is important to recognize that state-level renewable energy policies vary from state to state, and as a result, potential advantages for each production pathway also vary among states. For example, within the Rocky Mountain region, Colorado, Arizona, New Mexico, Utah, and Montana all have RPS, which may make them more favorable for biomass electricity production than Idaho and Wyoming, which do not have RPS [51]. Other conditions that affect financial outcomes, such as corporate tax rates and the regulatory environment, can also vary substantially among states. Wyoming, for example, does not collect state corporate income tax, which can reduce costs for any type of bioenergy business. Other facility siting considerations such as access to feedstock, access to product markets, availability of skilled labor, and availability of substitute energy products are likely to vary by state and affect financial outcomes.

\subsection{Forest Management Implications}

The baseline feedstock cost of $\$ 40$ per tonne was chosen because it is a realistic gate price for 3-inch wood chips in the region. However, the lower limit of $\$ 0$ per tonne used in the simulation is unrealistic except in the optimistic case of wood waste and byproducts that would otherwise be a liability with disposal costs. Much of the bioenergy produced by the forest sector through cogeneration of process heat and power is produced with such waste (e.g., pulping byproducts) or with low grade ground bark and slash (i.e., hog fuel). Even feedstock with low or zero procurement costs, such as logging residues, must be harvested, processed and transported to the facility, all of which incur substantial costs. In the case of biomass heat, the partner facility has a relatively small feedstock requirement, owns forestland and can generate its own feedstock from forest management activities, and its maximum price of $\$ 40$ per tonne may cover its production cost. For most other facilities, their gate price for feedstock must be carefully considered in the cost structure of their operations and reflects both the upstream cost of production and its market value for other uses.

As discussed previously, pyrolysis and gasification technologies tend to have narrower feedstock specifications than combustion for heat and power. Generally, this translates to higher feedstock costs. However, it appears from the results that the Biofuel and Pellet Scenarios can bear the cost of producing the clean, dry, small and uniform feedstock that these pathways require. In this case, harvesting beetle killed trees may have an advantage. If the trees are not suitable for traditional solid wood products such as lumber and are too distant from pulp mills to transport efficiently (which would drive up the price for roundwood and chips), tree stems can be efficiently delimbed, transported whole, debarked and processed at the facility. Biomass in this case would be transported as logs rather than chips, which tends to improve the efficiency of logistics, especially if the facility already has the equipment necessary for processing logs inside the gate. Combustion for heat and power has lower specifications and can generally use wetter, dirtier and coarser feedstocks, including ground up limbs and tree tops, which are less expensive, but TEA results show that these facilities also have a lower break even cost for feedstock.

Depending on site conditions, harvesting beetle killed trees can have several benefits, such as recovering economic value, reducing the spread of insects and disease, altering fire behavior to reduce 
fire risk, and improving conditions for regeneration. Often, salvaged trees can be used for lumber, paper and other products, and, when technically possible and economically viable, the tops, limbs and merchantable logs can be used for bioenergy. In many cases, harvesting the residual biomass for energy is seen as a marginal cost on the sawlog operation-in other words, the harvest of the higher value products makes biomass harvest possible. Rarely, if ever, is biomass harvest alone viewed as a profitable enterprise in this region, making biomass ventures dependent partly or wholly on the production and manufacture of traditional wood and fiber products. Although this industrial ecology has many benefits, it is not always possible in areas that have experienced decline in this sector. In the case of biofuels, pellets and biochar manufactured jointly, there is evidence that these enterprises may be able to wholly support the supply chain logistics needed to deliver feedstock to the gate, including feedstock from beetle kill salvage.

\section{Conclusions}

This study explored the financial viability of four existing or planned production pathway scenarios for the conversion of beetle-killed pine to bioenergy and bioproducts in the Rocky Mountain region of the United States. Monte Carlo simulation was used to account for uncertainty in key technoeconomic variables and to provide distributions of NPV, as well as sensitivity analysis for key variables. Maximum bearable feedstock price was used as a levelized metric of comparison across the scenarios, which varied in terms of scale of production and investment, and types of end products. Over a 20-year project period, results reveal average NPV ranging from a low of $-\$ 8.3$ million for electric power production, to $-\$ 24,000$ for institutional heating, to $\$ 22.4$ million for pellets with biochar, to a high of $\$ 76.0$ million for liquid biofuel and biochar. However, under simulation, all scenarios had conditions resulting in both positive and negative NPV. Maximum bearable feedstock price was \$26 per tonne for electric power production, \$39 for institutional heating, \$97 for pellets with biochar, and $\$ 227$ for liquid biofuels and biochar.

The large NPV for liquid biofuels and biochar reveals the high potential that new technology holds for profitably utilizing beetle kill pine in the $n$th plant phase under realistic market and policy conditions. However, the most appropriate technology can be expected to vary on a case-by-case basis depending on the quantity and quality of biomass available, the policy incentives that exist to reduce the cost of investment or operation, and the price of end products, as well as geographic variables not considered in this study. Because a variety of different conditions for biomass utilization exist throughout the Rockies, a variety of production pathways are needed to fill niches where they are most competitive, and where sufficient quantities of biomass are available from forest management activities across a region that is in need of forest restoration, but lacking a large conventional forest industry. Technoeconomic analyses like this one can help identify conditions that are likely to lead to success for bioeconomy entrepreneurs and stakeholders at all stages of the supply chain. Given the promising results for the Biofuel Scenario, further research into the production process and business landscape for liquid biofuel and biochar production is warranted. In particular, given the strong influence of biochar price and weak influence of biofuel price on NPV outcomes, and the potential for price volatility in the future as markets for biochar mature, the impact of market conditions on the decision space for producers of biofuel and biochar offers an intriguing topic for more detailed analysis.

Acknowledgments: We would like to acknowledge the industry partners who provided the expert opinion and information that was used to define our model scenarios: Mark Mathis and Jonah Levine from Confluence Energy in Kremmling, CO; Therese Glowacki from Boulder County, CO, Parks and Open Spaces Department; Brad Worsley from NOVO biopower in Snowflake, AZ; and Kendric Wait from Eagle Valley Clean Energy in Gypsum, CO. Kristin Brandt from Washington State University provided important advice and feedback on TEA and other analytical methods. This research, including the funds required for open access publication, was supported by AFRI Grant 2013-68005-21298 from the USDA National Institute of Food and Agriculture.

Author Contributions: Robert M. Campbell and Nathaniel M. Anderson conceived and designed the research project and wrote the paper. Robert M. Campbell collected and analyzed the technoeconomic dataset. 
Daren E. Daugaard provided technical expertise of bioenergy production and technoeconomic analysis techniques. Helen T. Naughton provided economic expertise and contributed to writing.

Conflicts of Interest: The authors declare no conflict of interest. The founding sponsors had no role in the design of the study; in the collection, analyses, or interpretation of data; in the writing of the manuscript, and in the decision to publish the results.

\section{References}

1. US Energy Information Administration. Monthly Energy Review; Table 1.3; US Energy Information Administration: Washington, DC, USA, 2017.

2. United States Congress. Energy Independence and Security Act of 2007. In Public Law; United States Congress: Washington, DC, USA, 2007; pp. 110-140.

3. Becker, D.; Moseley, C.; Lee, C. A supply chain analysis framework for assessing state-level forest biomass utilization policies in the United States. Biomass Bioenergy 2011, 35, 1429-1439. [CrossRef]

4. Ebers, A.; Malmsheimer, R.; Volk, T.; Newman, D. Inventory and classification of United States federal and state forest biomass electricity and heat policies. Biomass Bioenergy 2016, 84, 67-75. [CrossRef]

5. U.S. Department of Energy. 2016 Billion-Ton Report: Advancing Domestic Resources for a Thriving Bioeconomy, Volume 1: Economic Availability of Feedstocks; Langholtz, M.H., Stokes, B.J., Eaton, L.M., Eds.; ORNL/TM-2016/160; Oak Ridge National Laboratory: Oak Ridge, TN, USA, 2016.

6. Zanchi, G.; Pena, N.; Bird, N. Is woody bioenergy carbon neutral? A comparative assessment of emissions from consumption of woody bioenergy and fossil fuel. Glob. Chang. Biol. Bioenergy 2012, 4, 761-772. [CrossRef]

7. Buchholz, T.; Hurteau, M.D.; Gunn, J.; Saah, D. A global meta-analysis of forest bioenergy greenhouse gas emission accounting studies. GCB Bioenergy 2016, 8, 281-289. [CrossRef]

8. Wienk, C.L.; Sieg, C.H.; McPherson, G.R. Evaluating the role of cutting treatments, fire and soil seed banks in an experimental framework in ponderosa pine forests of the Black Hills, South Dakota. For. Ecol. Manag. 2004, 192, 375-393. [CrossRef]

9. Hutto, R.L. The ecological importance of severe wildfires: Some like it hot. Ecol. Appl. 2008, 18, $1827-1834$. [CrossRef] [PubMed]

10. Westerling, A.L.; Hidalgo, H.G.; Cayan, D.R.; Swetnam, T.W. Warming and earlier spring increase western U.S. forest wildfire activity. Science 2006, 313, 940-943. [CrossRef] [PubMed]

11. Littell, J.S.; McKenzie, D.; Peterson, D.L.; Westerling, A.L. Climate and wildfire area burned in western U.S. ecoprovinces, 1916-2003. Ecol. Appl. 2009, 19, 1003-1021. [CrossRef] [PubMed]

12. Miller, J.; Safford, H.; Crimmins, M.; Thode, A. Quantitative evidence for increasing forest fire severity in the Sierra Nevada and southern Cascade Mountains, California and Nevada, USA. Ecosystems 2009, 12, 16-32. [CrossRef]

13. Cansler, C.A.; McKenzie, D. Climate, fire size, and biophysical setting control fire severity and spatial pattern in the northern Cascade Range, USA. Ecol. Appl. 2014, 24, 1037-1056. [CrossRef] [PubMed]

14. Bentz, B.J.; Regniere, J.; Fettig, C.J.; Hansen, E.M.; Hicke, J.; Hayes, J.L.; Kelsey, R.; Negron, J.; Seybold, S. Climate change and bark beetles of the western U.S. and Canada: Direct and indirect effects. BioScience 2010, 60, 602-613. [CrossRef]

15. Chapman, T.B.; Veblen, T.T.; Schoennagel, T. Spatiotemporal patterns of mountain pine beetle activity in the southern Rocky Mountains. Ecology 2012, 93, 2175-2185. [CrossRef] [PubMed]

16. United States Department of Agriculture Forest Service. Western Bark Beetle Strategy. 2011. Available online: https:/ / www.fs.fed.us/restoration/Bark_Beetle/ (accessed on 24 January 2018).

17. Hart, S.J.; Veblen, T.T.; Eisenhart, K.S.; Jarvis, D.; Kulakowski, D. Drought induces spruce beetle (Dendroctonus rufipennis) outbreaks across northwestern Colorado. Ecology 2014, 95, 930-939. [CrossRef] [PubMed]

18. Gan, J.; Smith, C.T. Availability of logging residues and potential for electricity production and carbon displacement in the USA. Biomass Bioenergy 2006, 30, 1011-1020. [CrossRef]

19. Keefe, R.; Anderson, N.; Hogland, J.; Muhlenfeld, K. Woody Biomass Logistics: Cellulosic Energy Cropping Systems; Karlen, D., Ed.; John Wiley \& Sons: Hoboken, NJ, USA, 2014. 
20. McKendry, P. Energy production from biomass (part 2): Conversion technologies. Bioresour. Technol. 2002, 83, 47-54. [CrossRef]

21. Patel, M.; Kumar, X. Techno-economic and life cycle assessment on lignocellulosic biomass thermochemical conversion technologies: A review. Renew. Sustain. Energy Rev. 2016, 53, 1486-1499. [CrossRef]

22. Zhao, X.; Yao, G.; Tyner, W. Quantifying breakeven price distributions in stochastic techno-economic analysis. Appl. Energy 2016, 183, 318-326. [CrossRef]

23. Bridgwater, A.; Toft, A.; Brammer, J. A techno-economic comparison of power production by biomass fast pyrolysis with gasification and combustion. Renew. Sustain. Energy Rev. 2002, 6, 181-248. [CrossRef]

24. Sarkar, S.; Kumar, A.; Sultana, A. Biofuels and biochemical production from forest biomass in Western Canada. Energy 2011, 36, 6251-6262. [CrossRef]

25. Shabangu, S.; Woolf, D.; Fisher, E.; Angenent, L.; Lehmann, J. Techno-economic assessment of biomass slow pyrolysis into different biochar and methanol concepts. Fuel 2014, 117, 742-748. [CrossRef]

26. Beagle, E.; Belmont, E. Technoeconomic assessment of beetle kill biomass co-firing in existing coal fired power plants in the Western United States. Energy Policy 2016, 97, 429-438. [CrossRef]

27. Jones, S.; Meyer, P.; Snowden-Swan, L.; Padmaperuma, A.; Tan, E.; Dutta, A.; Jacobson, J.; Cafferty, K. Process Design and Economics for the Conversion of Lignocellulosic Biomass to Hydrocarbon Fuels; PNNL-23053; NREL/TP-5100-61178; Pacific Northwest National Laboratory: Richland, WA, USA; National Renewable Energy Laboratory: Golden, CO, USA; Idaho National Laboratory: Idaho Falls, ID, USA, 2013.

28. Pirraglia, A.; Gonzalez, R.; Saloni, D. Techno-economical analysis of wood pellets production for U.S. manufacturers. BioResources 2010, 5, 2374-2390.

29. Qian, Y.; McDow, W. The Wood Pellet Value Chain; U.S. Endowment for Forestry and Communities: Greenville, SC, USA, 2013.

30. US Energy Information Administration. Electric Power Annual: Average Price of Electricity to Ultimate Customers by End-Use Sector. 2016. Available online: https://www.eia.gov/electricity/annual/html/epa_ 02_10.html (accessed on 24 January 2018).

31. De Jong, S.; Hoefnagels, R.; Faaij, A.; Slade, R.; Mawhood, R.; Junginger, M. The feasibility of short-term production strategies for renewable jet fuels-A comprehensive techno-economic comparison. Biofuels Bioprod. Biorefin. 2015, 9, 778-800. [CrossRef]

32. Wright, M.; Daugaard, D.; Satrio, J.; Brown, R. Techno-economic analysis of biomass fast pyrolysis to transportation fuels. Fuel 2010, 89, S2-S10. [CrossRef]

33. Towler, G.; Sinnott, R. Chemical Engineering Design: Principles, Practice and Economics of Plant and Process Design; Butterworth-Heinemann: Oxford, UK, 2013.

34. Swanson, R.; Platon, A.; Satrio, J.; Brown, R. Techno-economic analysis of biomass-to-liquids production based on gasification. Fuel 2010, 89, S11-S19. [CrossRef]

35. Peters, M.; Timmerhaus, K.; West, R. Plant Design and Economics for Chemical Engineers, 5th ed.; McGraw Hill: Boston, MA, USA, 2003.

36. US Bureau of Labor Statistics. Occupational Employment Statistics. 2017. Available online: https://www. bls.gov/oes / (accessed on 24 January 2018).

37. Bergman, R.; Maker, T. Fuels for Schools: Case Study in Darby, Montana; General Technical Report FPL-GTR-173; Madison, W.I., Ed.; U.S. Department of Agriculture, Forest Service, Forest Products Laboratory: Madison, WI, USA, 2007; 21p.

38. Sprow, F. Evaluation of research expenditures using triangular distribution functions and Monte Carlo methods. Ind. Eng. Chem. 1967, 59, 35-38. [CrossRef]

39. Kim, D.; Anderson, N.; Chung, W. Financial performance of a mobile pyrolysis system used to produce biochar from sawmill residues. For. Prod. J. 2015, 65, 189-197. [CrossRef]

40. U.S. Energy Information Administration. Petroleum and Other Liquids Data: New York Harbor No. 2 Heating Oil Future Contract 1. 2017. Available online: https:/ /www.eia.gov/dnav/pet/hist/LeafHandler. ashx?n=PET\&s=EER_EPD2F_PE1_Y35NY_DPG\&f=A (accessed on 24 January 2018).

41. U.S. Energy Information Administration. Petroleum and Other Liquids Data: New York Harbor Reformulated RBOB Regular Gasoline Future Contract 1. 2017. Available online: https://www. eia.gov/dnav/pet/hist/LeafHandler.ashx?n=PET\&s=EER_EPMRR_PE1_Y35NY_DPG\&f=A (accessed on 24 January 2018). 
42. U.S. Energy Information Administration. Henry Hub Natural Gas Spot Price. 2017. Available online: http:/ / tonto.eia.gov/dnav/ng/hist/rngwhhdm.htm (accessed on 24 January 2018).

43. U.S. Environmental Protection Agency. Biomass Combined Heat and Power Catalog of Technologies; U.S. Environmental Protection Agency Combined Heat and Power Partnership: Washington, DC, USA, 2007.

44. Fantozzi, F.; Bartocci, P.; D’Alessandro, B.; Arampatzis, S.; Manos, B. Public-private partnerships value in bioenergy projects: Economic feasibility analysis based on two case studies. Biomass Bioenergy 2014, 66, 387-397. [CrossRef]

45. U.S. Department of Agriculture. USDA Awards Funds to Expand, Accelerate Wood Energy and Wood Products Markets in 19 States. USDA Press Release No. 0115.16; $2016 . \quad$ Available online: https: / www.usda.gov / media/press-releases/2016/05/13/usda-awards-funds-expand-acceleratewood-energy-and-wood-products (accessed on 24 January 2018).

46. U.S. Department of Energy. Loan Programs Office: Bioenergy and Biofuels Projects. 2017. Available online: https:/ / energy.gov/lpo/bioenergy-biofuels-projects (accessed on 24 January 2018).

47. Aguilar, F.; Song, N.; Shifley, S. Review of consumption trends and public policies promoting woody biomass as an energy feedstock in the US. Biomass Bioenergy 2011, 35, 3708-3718. [CrossRef]

48. Couture, T.; Cory, K.; Kreycik, C.; Williams, E. A Policymaker's Guide to Feed-in Tariff Policy Design; Technical Report: NREL/TP-6A2-44849; National Renewable Energy Laboratory: Golden, CO, USA, 2010.

49. O'Shaughnessy, E.; Heeter, J.; Liu, C.; Nobler, E. Status and Trends in the U.S. Voluntary Green Power Market (2014 Data); Technical Report: NREL/TP-6A20-65252; National Renewable Energy Laboratory: Golden, CO, USA, 2015.

50. US Federal Register. Biomass Crop Assistance Program; Final Rule. 7 CFR Part 1450; USDA: Washington, DC, USA, 2010; Volume 75, pp. 66202-66243.

51. NC Clean Energy Technology Center. Database of State Incentives for Renewables and Efficiency; North Carolina State University: Raleigh, NC, USA, 2018.

(C) 2018 by the authors. Licensee MDPI, Basel, Switzerland. This article is an open access article distributed under the terms and conditions of the Creative Commons Attribution (CC BY) license (http:// creativecommons.org/licenses/by/4.0/). 